\title{
Pola Distribusi dan Kerapatan Pandanus sarasinorum Warb., Pandan Endemik Sulawesi di Hutan Pegunungan sekitar Danau Kalimpa'a Taman Nasional Lore Lindu
}

\section{The distribution pattern and density of Pandanus sarasinorum Warb., an Endemic Pandan of Sulawesi in the mountain forest around Kalimpa'a Lake Lore Lindu National Park}

\author{
Iring R. F. Kambuno ${ }^{1}$, Ramadanil ${ }^{1}$ dan Moh. Iqbal ${ }^{1}$ \\ ${ }^{1}$ Jurusan Biologi Fakultas Matematika dan Ilmu Pengetahuan Alam Universitas Tadulako
}

\begin{abstract}
The research about "The distribution pattern and density of Pandanus sarasinorum Warb., an endemic pandan of Sulawesi in the mountain forest around Kalimpa'a Lake Lore Lindu National Park" was conducted from March tol May 2018. The research aimed to know the distribution pattern and density of Pandanus sarasinorum Warb. in the studied area by using purposive sampling with 7 transect sized 50x10 m and small plot sized 10x10 m each transect. The result showed that distribution pattern of Pandanus sarasinorum Warb. is clumped. The highest density for adult was found in transect 5 with density 340 and relative density $25,37 \%$ and the lowest density was found in transect number 7 with density 100 and relative density $7,47 \%$. The highest density for seedling was found in transect number 4 with density 60 and relative density $37,5 \%$ and the lowest density was found in transect number 3 with density 20 and relative density $12,5 \%$.
\end{abstract}

Key words: Pandanus sarasinorum Warb., Distribution Pattern and Density, Lore Lindu National Park.

\begin{abstract}
ABSTRAK
Penelitian ini berjudul "Pola Distribusi dan Kerapatan Pandanus sarasinorum Warb., pandan endemik Sulawesi di hutan pegunungan sekitar danau Kalimpa'a Taman Nasional Lore Lindu" yang dilaksanakan dari bulan Maret sampai Mei 2018. Penelitian bertujuan untuk mengetahui pola distribusi dan kerapatan Pandanus sarasinorum Warb. di hutan pegunungan sekitar danau Kalimpa'a Taman Nasional Lore Lindu. Penelitian ini menggunakan metode purposive sampling dengan 7 buah transek yang berukuran $50 \times 10 \mathrm{~m}$ beserta plot kecil $10 \times 10 \mathrm{~m}$ di dalamnya. Hasilnya menunjukan pola distribusi Pandanus sarasinorum Warb. adalah pola mengelompok. Kerapatan tertinggi untuk tingkat dewasa, terdapat pada transek kelima dengan nilai kerapatan 340 dan kerapatan relatif 25,37\%, sedangkan kerapatan terendah terdapat pada transek ketujuh dengan nilai kerapatan 100 dan kerapatan relatif $7,47 \%$. Kerapatan tertinggi untuk tingkat anakan, terdapat pada transek keempat dengan nilai kerapatan 60 dan kerapatan relatif 37,5\%, sedangkan kerapatan terendah terdapat pada transek ketiga dengan nilai kerapatan 20 dan kerapatan relatif $12,5 \%$.
\end{abstract}

Kata kunci: Pandanus sarasinorum Warb., Pola Distribusi dan Kerapatan, Taman Nasional Lore Lindu 


\section{LATAR BELAKANG}

Indonesia memiliki keanekaragaman dan penyebaran famili Pandanaceae yang tinggi, khususnya genus Pandanus. Terdapat sekitar 700 jenis Pandanus yang tersebar di berbagai daerah, diantaranya Sumatera, Jawa, Bali, Sulawesi, Kalimantan, Maluku dan Papua (Stone, 1982).

Sulawesi memiliki sekitar $15 \%$ tumbuhan berbunga endemik (Pitopang, 2006). Balgooy et al., (1996) melaporkan bahwa terdapat 933 jenis tumbuhan di Sulawesi dan 112 jenis diantaranya adalah endemik. Salah satunya adalah Pandanus sarasinorum Warb.

Taman Nasional Lore Lindu (TNLL) merupakan perwakilan dari keanekaragaman hayati yang terletak di bioregion Wallacea. TNLL merupakan kawasan yang di dominasi oleh $90 \%$ hutan pegunungan dengan ketinggian 1.000-2.500 $m$ dpl dan sisanya adalah hutan dataran rendah dengan ketinggian 200-1.000 m dpl (Pitopang, 2006). Kawasan TNLL memiliki kondisi yang masih alami dan kaya akan keberagaman jenis tumbuhan, khususnya tumbuhan endemik Sulawesi (Kementrian Lingkungan Hidup dan Kehutanan, 2015).

Pandanus sarasinorum Warb. merupakan salah satu jenis dari genus Pandanus, biasanya disebut "Pondo" oleh masyarakat Desa Sedoa. Hidup pada hutan hujan tropika pada dataran rendah hingga dataran tinggi dengan ketinggian mencapai 500-1.500 m dpl. Jenis pandan ini banyak tumbuh pada daerah lembab dan rawa (Keim, 2007).

Tumbuhan Pandanus sarasinorum Warb. mudah dikenali keberadaannya saat di lapangan karena adanya akar penopang (poop roots) yang tumbuh tinggi dan kokoh. Perbuahannya adalah perbuahan tandan (spika) yang tersusun atas 10-12 cephalia, tiap cephalium memiliki bentuk bulat-lonjong bersegi tiga, tangkai bakal buah (style) berbentuk duri meruncing tajam dan irisan melintang cephalium sangat nyata berbentuk segi tiga (Keim, 2007).

Kajian mengenai keanekaragaman Pandanaceae di Sulawesi Tengah telah beberapa kali dilakukan (Keim, 2007), namun tidak disertai informasi mengenai pola distribusi dan kerapatannya. Oleh karena itu, penelitian mengenai pola distribusi dan kerapatan jenis tersebut perlu dilakukan untuk menambah data ekologi di Sulawesi, khususnya di Taman Nasional Lore Lindu.

\section{BAHAN DAN METODE}

Penelitian dilaksanakan pada bulan Maret sampai Mei 2018 di Hutan Pegunungan sekitar Danau Kalimpa'a Taman Nasional Lore Lindu dan di Laboratorium Biodiversity Jurusan Biologi 
Fakultas Matematika dan Ilmu Pengetahuan

Alam Universitas Tadulako.

Alat yang digunakan pada penelitian ini yaitu GPS (Global Position System), meteran, gunting stek, parang, soil tester, lux meter, sasak, kamera, oven, buku lapangan. Bahan yang digunakan pada penelitian ini yaitu karung, koran, tali raffia, spritus, plastik sampel dan label gantung.

Metode yang digunakan pada penelitian ini adalah metode Purposive sampling. Metode purposive sampling merupakan metode yang meletakkan transek secara sengaja (Fachrul, 2007). Metode ini dilakukan dengan cara membuat transek pada lokasi yang ditumbuhi $P$. sarasinorum. Pembuatan plot dimulai dengan pembuatan 7 buah garis transek dengan ukuran 50x10 m yang di dalamnya terdapat plot kecil berukuran 10x10 m.

Pembuatan Herbarium menggunakan metode Schweinfurth Method (Bridson and Forman, 1989). Sampel Pandanus sarasinorum Warb. yang didapatkan di lapangan diawetkan menggunakan spritus kemudian disusun di dalam sasak. Sampel yang telah diawetkan, dimasukkan ke dalam oven yang berada di Laboratorium Biodiversity. Setelah kering, sampel diberi label.

\section{HASIL}

\section{Pola Distribusi}

Menurut Krebs (1989), Indeks Morisita $\left(I_{d}\right)$ digunakan untuk mengetahui pola distribusi $P$. sarasinorum Warb., dengan persamaan sebagai berikut:

$$
I d=n \frac{\left(\sum x^{2}-\sum x\right)}{\left(\sum x\right)^{2}-\sum x}
$$

Keterangan:

Id = Indeks Morisita

$\mathrm{n} \quad=$ Jumlah seluruh transek

$\sum \mathrm{x}=$ Jumlah individu per transek

$\left(\sum \mathrm{x}\right)^{2}=$ Jumlah kuadrat total individu

Nilai Indeks Morisita yang diperoleh, dapat diartikan sebagai berikut:

$\mathrm{I}_{\mathrm{d}}=0$ Pola acak

$\mathrm{I}_{\mathrm{d}}>0$ Pola mengelompok

$\mathrm{I}_{\mathrm{d}}<0$ Pola seragam

\section{a. Kerapatan}

Menurut Fachrul (2007), kerapatan memberikan gambaran mengenai komposisi jenis suatu komunitas. Kerapatan (density) dapat dihitung dengan menggunakan rumus sebagai berikut:

Kerapatan $=\frac{\text { Jumlah individu }}{\text { Luas area (Ha) }}$

Kerapatan Relatif $=\frac{\text { Kerapatan suatu jenis }}{\text { Kerapatan seluruh jenis }} \times 100 \%$ 


\section{Deskripsi P. sarasinorum Warb. S}
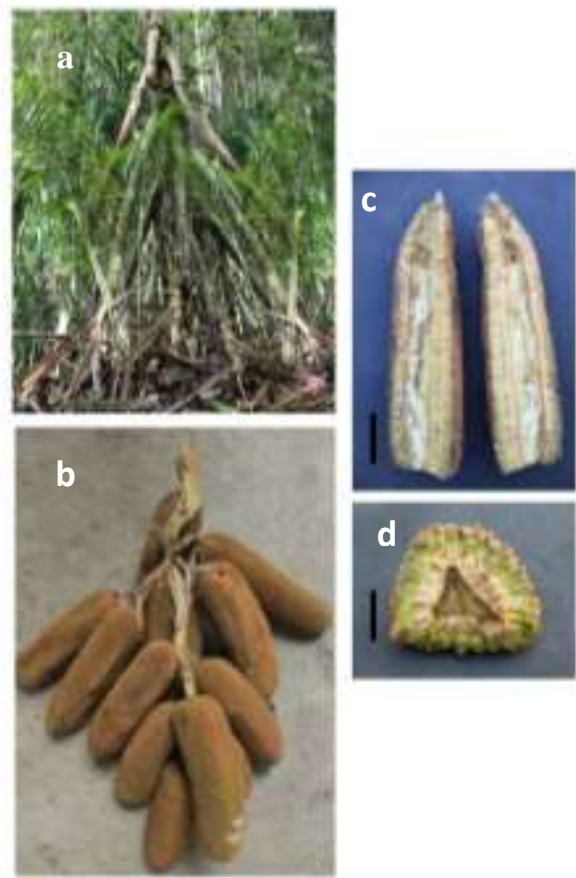

Gambar 1. Perawakan P. sarasinorum Warb.

a. Akar penopang $P$. sarasinorum Warb. (prop root)

b. Perbuahan tandan $P$. sarasinorum Warb.

c. Irisan membujur cephalium

d. Irisan melintang cephalium

Panjang garis pada gambar $\mathrm{c}$ dan $\mathrm{d}$ : $4 \mathrm{~cm}$.

Tumbuhan $P$. sarasinorum Warb. merupakan salah satu jenis pandan endemik pulau Sulawesi yang memiliki perawakan pohon dengan tinggi $>10 \mathrm{~m}$, mudah dikenali dengan adanya akar penopang (prop rots), daun berwarna hijau, pinggiran daun berduri, panjang daun 140x7 cm, buah berwarna kuning kecokelatan, perbuahan tandan yang terdiri atas 10-12 cephalia, irisan membujur cephalium berbentuk bulat lonjong, irisan melintang cephalium berbentuk segitiga, bakal buah (style) berbentuk duri meruncing tajam dan panjang buah $16 \mathrm{~cm}$.

\section{Gambaran Lokasi Penelitian}

Lokasi penelitian terletak di hutan pegunungan sekitar danau Kalimpa'a Taman Nasional Lore Lindu. Hutan pegunungan tersebut masuk ke dalam wilayah Desa Sedoa, Kabupaten Poso. Lokasi penelitian terletak pada ketinggian 1698-1751 m dpl.

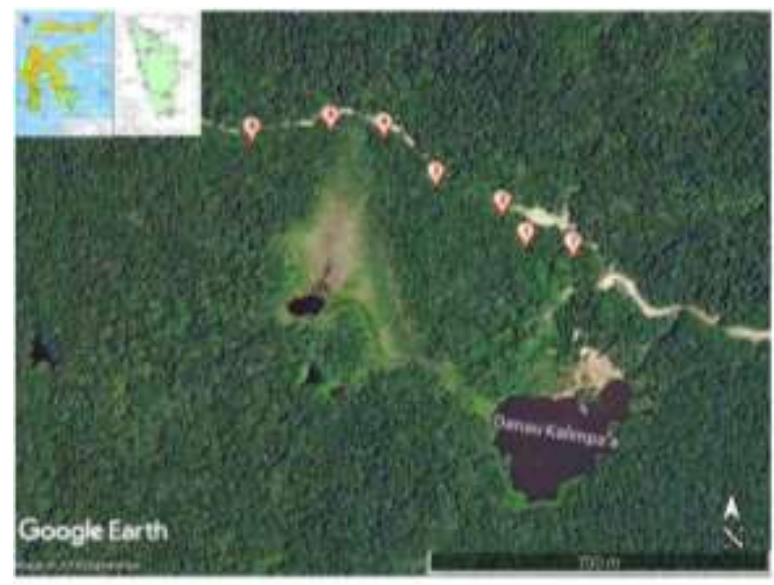

Gambar 2. Peta Lokasi Penelitian

Tabel 1. Data Ekologi Lokasi Penelitian

\begin{tabular}{|c|c|c|c|c|c|c|}
\hline No. & Transek & Titik Koordinat & $\begin{array}{c}\text { Ketinggian } \\
\text { (m dpl) }\end{array}$ & $\begin{array}{c}\text { pH } \\
\text { Tanah }\end{array}$ & $\begin{array}{c}\text { Kelembaban } \\
\text { Tanah }(\%)\end{array}$ & $\begin{array}{c}\text { Intensitas } \\
\text { Cahaya }(\mathrm{Cd})\end{array}$ \\
\hline 1. & I & $01^{\circ} 19^{\prime} 25.68^{\prime \prime S}, 120^{\circ} 18^{\prime} 25.47^{\prime \prime E}$ & 1723 & 5,2 & 55 & 980 \\
\hline 2. & II & $01^{\circ} 19^{\prime} 23.24^{\prime \prime S}, 120^{\circ} 18^{\prime} 24.37^{\prime \prime} \mathrm{E}$ & 1695 & 5,3 & 50 & 1220 \\
\hline 3. & III & $01^{\circ} 19^{\prime} 20.82^{\prime \prime S}, 120^{\circ} 18^{\prime} 19.84^{\prime \prime E}$ & 1712 & 4,4 & 65 & 240 \\
\hline 4. & IV & $01^{\circ} 19^{\prime} 17.77^{\prime \prime S}, 120^{\circ} 18^{\prime} 16.26^{\prime \prime} \mathrm{E}$ & 1730 & 5,4 & 40 & 1340 \\
\hline 5. & $\mathrm{~V}$ & $01^{\circ} 19^{\prime} 17.15^{\prime \prime S}, 120^{\circ} 18^{\prime} 12.42^{\prime \prime} \mathrm{E}$ & 1751 & 6,2 & 30 & 1360 \\
\hline 6. & VI & $01^{\circ} 19^{\prime} 18.25^{\prime \prime S}, 120^{\circ} 18^{\prime} 06.6^{\prime \prime} \mathrm{E}$ & 1736 & 5,3 & 50 & 1240 \\
\hline 7. & VII & $01^{\circ} 19^{\prime} 25.44^{\prime \prime S}, 120^{\circ} 18^{\prime} 29.44^{\prime \prime E}$ & 1698 & 6,4 & 15 & 1440 \\
\hline
\end{tabular}


Tabel 2. Pola Distribusi Pandanus sarasinorum Warb. di Hutan Pegunungan sekitar Danau Kalimpa'a TNLL

\begin{tabular}{cccccc}
\hline \multirow{2}{*}{ No. } & \multirow{2}{*}{ Transek } & \multicolumn{2}{c}{ Jumlah Individu } & \multicolumn{2}{c}{ Pola Penyebaran } \\
\cline { 3 - 6 } & & Anakan & Dewasa & Anakan & Dewasa \\
\hline 1. & I & 2 & 7 & Mengelompok & Mengelompok \\
2. & II & - & 6 & - & Mengelompok \\
3. & III & 1 & 12 & Acak & Mengelompok \\
4. & IV & 3 & 14 & Mengelompok & Mengelompok \\
5. & V & - & 17 & - & Mengelompok \\
6. & VI & 2 & 6 & Mengelompok & Mengelompok \\
7. & VII & - & 5 & - & Mengelompok \\
\hline Keterangan & (-), Tidak ditemukan tumbuhan Pandanus sarasinorum Warb.
\end{tabular}

Tabel 3. Kerapatan Pandanus sarasinorum Warb. di Hutan Pegunungan sekitar Danau Kalimpa'a TNLL

\begin{tabular}{cccccc}
\hline & & \multicolumn{2}{c}{ Kerapatan } & \multicolumn{2}{c}{ Kerapatan Relatif } \\
No. & Transek & \multicolumn{2}{c}{ Anakan (\%) } & Dewasa (\%) \\
\cline { 3 - 6 } & & Anakan & Dewasa & & \\
\hline 1. & I & 40 & 140 & -25 & 10,45 \\
2. & II & - & 120 & 12,5 & 17,95 \\
3. & III & 20 & 240 & 37,5 & 20,90 \\
4. & IV & 60 & 280 & - & 25,37 \\
5. & V & - & 340 & 25 & 7,95 \\
6. & VI & 40 & 120 & - & 100 \\
7. & VII & - & 100 & 100 & \\
\hline
\end{tabular}

Tumbuhan $P$. sarasinorum Warb. memiliki pola distribusi secara mengelompok dan acak. Pola mengelompok ditandai dengan nilai Indeks Morisita lebih besar dari nol (Id $>0)$ dan pola acak ditandai dengan nilai Indeks Morisita sama dengan nol $(\mathrm{Id}=0)$. Secara keseluruhan, pola distribusi $P$. sarasinorum Warb. adalah mengelompok, walaupun terdapat satu transek yang menghasilkan pola acak. Transek yang menghasilkan pola acak adalah transek ketiga. Transek ketiga hanya memiliki 1 individu anakan. Jumlah individu tersebut, tidak dapat membentuk pola dan setelah diolah ke dalam Indeks Morisita akan menghasilkan pola acak $(\mathrm{Id}=0)$.
Kebanyakan jenis tumbuhan berkembang biak dengan biji. Biji yang dihasilkan akan menyebar lalu tumbuh dekat dengan tubuh induknya. Pertumbuhan individu baru dari suatu jenis tumbuhan akan membentuk pola-pola tertentu yang disebut pola distribusi. Pola yang umumnya ditemukan adalah pola mengelompok dibandingkan pola acak dan seragam (Djufri, 2002). Pola mengelompok terjadi karena pertumbuhan suatu jenis tumbuhan didukung oleh kondisi lingkungan yang sesuai dengan kebutuhan hidupnya (Siti, 2012). Setiap jenis tumbuhan dapat hidup pada kondisi lingkungan yang berada dalam kisaran toleransi tertentu (Suin, 2002). 
Kerapatan tertinggi $P$. sarasinorum Warb. untuk tingkat dewasa, terletak pada transek kelima dengan nilai kerapatan 340 dan kerapatan relatif $25,37 \%$. Kerapatan terendah untuk tingkat dewasa, terletak pada transek ketujuh dengan nilai kerapatan 100 dan kerapatan relatif 7,47\%. Kerapatan tertinggi $P$. sarasinorum Warb. untuk tingkat anakan, terletak pada transek keempat dengan nilai kerapatan 60 dan kerapatan relatif $37,5 \%$. Kerapatan terendah untuk tingkat anakan, terletak pada transek ketiga dengan nilai kerapatan 20 dan nilai kerapatan relatif $12,5 \%$ (Tabel $3)$.

Berdasarkan total kerapatan individu Pandanus sarasinorum Warb. (Tabel 3.), hasil menunjukkan bahwa individu anakan berada pada tingkat jarang dan pada individu dewasa hasilnya menunjukkan individu dewasa berada pada tingkat sedang. Kaunang dan Kimball, (2009), menyatakan bahwa pada fase semai (anakan) tingkat jarang berada pada kisaran nilai $<1,000$, sedangkan pada fase pohon (dewasa), tingkat sedang berada pada kisaran nilai kerapatan 750-1,500.

Kondisi lingkungan memiliki pengaruh bagi kelangsungan hidup dan proses reproduksi suatu jenis tumbuhan. Tumbuhan yang dapat hidup dan berkompetisi dengan jenis tumbuhan lain, akan terus bertumbuh dan berkembang biak. Proses tersebut, tidak lepas dari adanya hubungan antara suatu jenis tumbuhan dengan kondisi lingkungannya. Hubungan itu saling mempengaruhi satu sama lain. Jika suatu individu dapat bertoleransi dengan kondisi lingkungannya, maka jumlah individu dari suatu jenis tumbuhan akan semakin besar. Besarnya jumlah individu, akan mempengaruhi nilai kerapatan dan pola distribusi suatu jenis tumbuhan.

Berdasarkan hasil penelitian, terdapat beberapa transek yang tidak memiliki $P$. sarasinorum Warb. Transek tersebut diantaranya transek kedua, kelima dan ketujuh. Jumlah individu $P$. sarasinorum Warb. yang terdapat di dalam transek dapat menunjukkan keadaan lingkungan yang sesuai bagi pertumbuhannya. Semakin banyak jumlah $P$. sarasinorum Warb. yang tumbuh, menandakan $P . \quad$ sarasinorum Warb. toleran dengan kondisi lingkungan tersebut.

P. sarasinorum Warb. merupakan salah satu jenis tumbuhan yang dapat hidup di berbagai macam habitat, mulai dari daerah lembab, berair maupun berawa (Keim, 2007). Setiap transek memiliki kondisi lingkungan yang berbeda-beda dan memiliki beragam jenis tumbuhan, beberapa diantaranya adalah jenis tumbuhan yang termasuk dalam genus Zingiberaceae dan Arecaceae. Berdasarkan data ekologi (Tabel 1.) P. sarasinorum Warb. dapat hidup dengan kondisi 
lingkungan yang lembab dengan $\mathrm{pH}$ yang

tidak terlalu asam serta intensitas cahaya matahari yang cukup seperti kondisi lingkungan yang berada di Hutan Pegunungan sekitar Danau Kalimpa'a

Taman Nasional Lore Lindu.

\section{DAFTAR PUSTAKA}

Bridson, D. and L. Forman. (1989). The Herbarium Handbook. Kew. London: The Royal Botanic Garden of Kew.

Djufri. (2002). Penentuan Pola Distribusi, Asosiasi dan Interaksi Spesies Tumbuhan Khususnya Padang Rumput di Taman Nasional Baluran, Jawa Timur. Jurnal Biodiversitas, 3(1), 181188.

Fachrul, M. F. (2007). Metode Sampling Bioekologi. Jakarta: Bumi Aksara.

Kaunang, T. D., dan Kimball, J. D. (2009). Komposisi dan Struktur Vegetasi Hutan Mangrove di Taman Nasional Bunaken Sulawesi Utara. Agritek, 17(6), 1-10.

Keim, A. P. (2007). Keanekaragaman Suku Pandanaceae di Pegunungan Sekitar Desa Sedoa, Kawasan Taman Nasional Lore Lindu, Kabupaten Poso-Propinsi Sulawesi Tengah. Berita Biologi, 8(5), 311-413.

Kementrian Lingkungan Hidup dan Kehutanan. (2015). BIOSFER: Berita, Informasi, Opini, Seni, Fakta, Edukasi dan Ruang Kreasi. Palu: Balai Besar Taman Nasional Lore Lindu.

Krebs, C. J. (1989). Ecology: The Experimental Analysis of Distribution and Abundance. New York: Harper \& Row Publishing.

Pitopang, R. (2006). Structure and Composition of Six Land Use Types Differing in Use Intensity in the Lore Lindu National Park, Central Sulawesi, Indonesia. PhD Disertation. Post
Graduate Program. Bogor: Bogor Agricultural University.

Siti, M. (2012). Keanekaragaman, Pola Sebaran dan Asosiasi Nepenthes di Hutan Kerangas Kabupaten Belitung Timur Provinsi Kepulauan Bangka Belitung. Skripsi. Bogor: Fakultas Kehutanan, IPB.

Stone, B. C. (1982). New Guinea Pandanaceae: First Approach to Ecology and Biogeography. In Gressitt, J. L. (Ed.), Biogeography and Ecology of New Guinea Vol. 1. Monographiae Biologicae 42. The Hague: Dr. W. Junk Publ.

Suin, N. M. (2002). Metode Ekologi. Padang: Universitas Andalas.

van Balgooy, M. M. J., Hovenkamp P. H., Welzen P. C. (1996). Phytogeography of the Pasific Floristic and historical distribution pattern in plant. In The origin and evolution of Pasific island biotas. New Guinea to eastern Polynesia; pattern and process 191213. Keast, A, and Miller, S.A (Ed.). Amsterdam: SPB academic Publishing.

Pola Distribusi dan Kerapatan Pandanus sarasinorum Warb., Pandan Endemik Sulawesi di Hutan Pegunungan sekitar Danau Kalimpa'a Taman Nasional Lore Lindu 